\title{
Student Perceptions of Soft Skills Activities in Professional Level Athletic Training Programs
}

Christina Davlin-Pater

Xavier University, davlin@xavier.edu

Elisabeth C. Rosencrum

Plymouth State University, ecrosencrum@plymouth.edu

Follow this and additional works at: https://nsuworks.nova.edu/ijahsp

Part of the Medicine and Health Sciences Commons

\section{Recommended Citation}

Davlin-Pater C, Rosencrum EC. Student Perceptions of Soft Skills Activities in Professional Level Athletic Training Programs. The Internet Journal of Allied Health Sciences and Practice. 2021 Jan 01;19(3), Article 17.

This Manuscript is brought to you for free and open access by the College of Health Care Sciences at NSUWorks. It has been accepted for inclusion in Internet Journal of Allied Health Sciences and Practice by an authorized editor of NSUWorks. For more information, please contact nsuworks@nova.edu. 


\title{
Student Perceptions of Soft Skills Activities in Professional Level Athletic Training Programs
}

\begin{abstract}
Purpose: Educators should not assume that students will acquire the soft skills and professional behaviors that are valued without instruction and guided practice. Early establishment of a positive professional identity may empower and motivate students to work towards excellence. We sought to explore and describe student perceptions of online learning modules designed to promote soft skill development in professional level athletic training students early in their education program. Methods: A qualitative approach was used. We designed a course curriculum using a series of online learning modules to promote the development of soft skills and the appreciation of professional values. It was implemented at two universities with professional-level masters of athletic training programs. Students completed the curriculum in the first term in their respective programs. Participants included a convenience sample of 14 students enrolled in two masters-level professional athletic training programs. We invited students enrolled in two targeted programs to participate in the study by email and in person. We collected data in the form of survey and semi structured focus group interview responses as well as student artifacts from the courses. We analyzed the data in an ongoing, inductive, constant comparative manner, and the researchers used peer debriefing and member checking to enhance data trustworthiness. Results: Participants appreciated attention to professional behaviors in a modality that was time-efficient and through a scope relevant to their practice. Three main themes emerged from the data including the value of soft skills, interpersonal communication and collaboration, and personal growth. Conclusions: Athletic training educators should consider overt attention to teaching soft skills and professional behaviors. Educators should also consider doing so in a manner that is perceived as valuable to students.
\end{abstract}

\section{Author Bio(s)}

Christina Davlin-Pater, Ph.D., AT, ATC, EMT, is an Associate Professor of athletic training at Xavier University. She also serves as the Director of the Master of Science in Athletic Training Program at Xavier University.

Elisabeth C Rosencrum, PhD, NH-LAT, ATC, CSCS, is an Assistant Professor of athletic training and allied health sciences at Plymouth State University. 


\title{
1IVAHSP \\ The Internet Journal of Allied Health Sciences and Practice \\ Vol. 19 No. 3 ISSN 1540-580X
}

\section{Student Perceptions of Soft Skills Activities in Professional Level Athletic Training Programs}

\author{
Christina Davlin-Pater ${ }^{1}$ \\ Elisabeth C. Rosencrum² \\ 1. Xavier University \\ 2. Plymouth State University
}

United States

\begin{abstract}
Purpose: Educators should not assume that students will acquire the soft skills and professional behaviors that are valued without instruction and guided practice. Early establishment of a positive professional identity may empower and motivate students to work towards excellence. We sought to explore and describe student perceptions of online learning modules designed to promote soft skill development in professional level athletic training students early in their education program. Methods: A qualitative approach was used. We designed a course curriculum using a series of online learning modules to promote the development of soft skills and the appreciation of professional values. It was implemented at two universities with professional-level masters of athletic training programs. Students completed the curriculum in the first term in their respective programs. Participants included a convenience sample of 14 students enrolled in two masters-level professional athletic training programs. We invited students enrolled in two targeted programs to participate in the study by email and in person. We collected data in the form of survey and semi structured focus group interview responses as well as student artifacts from the courses. We analyzed the data in an ongoing, inductive, constant comparative manner, and the researchers used peer debriefing and member checking to enhance data trustworthiness. Results: Participants appreciated attention to professional behaviors in a modality that was time-efficient and through a scope relevant to their practice. Three main themes emerged from the data including the value of soft skills, interpersonal communication and collaboration, and personal growth. Conclusions: Athletic training educators should consider overt attention to teaching soft skills and professional behaviors. Educators should also consider doing so in a manner that is perceived as valuable to students.
\end{abstract}

Key Words: professionalism, pedagogy, online learning, soft-skills, athletic training education 


\section{INTRODUCTION}

"Soft Skills" as a concept are well-established in the healthcare education literature, regardless of field. It is an umbrella term for social skills and professional skills. ${ }^{1}$ Soft skills may also include personality traits and qualities such as confidence, honesty, empathy, adaptability and optimism..$^{2,3}$ Over time, they have been included in educational competencies and standards established by accreditation agencies for a variety of health care professionals. . $^{4} 6$ The 2020 Standards for Accreditation of Professional Athletic Training Programs include competencies for professionalism and quality patient care. The competencies contain many soft skills including: honesty, responsibility, ethical behavior, communication, accountability, and respectful behavior. ${ }^{4}$ Additionally, time management, initiative, self-confidence,humility, adaptability, and resiliency have been noted as valuable to athletic trainers, employers, and preceptors. ${ }^{7-10}$ Even though the importance of soft skills is well established in athletic training literature, more attention is needed regarding how best to integrate soft skills into a curriculum. ${ }^{7-15}$

In 2010, Tsang described a unique conceptual approach to developing professionalism and professional identity in health care students. ${ }^{16}$ Tsang proposed that students should be recognized as "evolving professionals." According to the evolving professional approach, this perspective encourages socialization and formation of a professional identity which is needed to optimize learning and professional development. It also recognizes that students exist in a supportive environment and that student transformation occurs collaboratively under the basic tenant that professional behaviors need to be developed and practiced. Tsang cautions against assuming that students will simply adopt the soft skills we value casually during practice. ${ }^{16,17}$ Other authors have also cautioned against relying on an informal or hidden curriculum method for teaching professionalism, suggesting that a formal curriculum emphasizes to students the importance of shared professional values and behaviors. . $8,19^{1}$

Embracing the "evolving professionals" concept means that we choose, as educators, to bring professionalism explicitly into the curriculum with the goal of "supporting, influencing, motiving, and inspiring learners to become [athletic trainers] of excellence."17(p3) By explicitly integrating content focused on soft skill development at the beginning of the professional education program, we aim to promote professional socialization and guide students in establishing a constructive professional identity that will empower them in a variety of ways. Previous researchers found that early professional socialization encourages deep learning by showing students connections and context. $16,20 \mathrm{It}$ also promotes a sense of belonging and formation of a professional identity that can be a significant motivational force. ${ }^{16,20-23}$

Despite support for devoting quality time and energy to the development of soft skills and professional behaviors in a formal curriculum, there is currently no literature in athletic training education regarding the examination of using online modules for this purpose. Without being trained in the soft skills which complement the technical skills of athletic training, students may not adequately develop them. Use of online modules could allow for efficient and effective promotion of soft skills and professional values without sacrificing valuable in-class time. The goal of adding important content while maintaining in-class time for instruction of other athletic training skills led the researchers to the current program design. The aim of this study is to explore and describe student perceptions of online learning modules designed to promote soft skill development in professional level athletic training students during their first term in their education program.

\section{METHODS}

A phenomenological approach was used to understand the experiences of the participants with a focus on the commonality of those experiences. ${ }^{24,25}$ The aim was to examine the perceptions and subjective judgements of the participants without a predetermined framework. The findings presented in this article are focused on participants' experiences related to the online soft skill modules.

\section{Design and Setting}

This qualitative study occurred at one public University in the northeast and one private mid-western University of similar size both supporting accredited professional-level masters programs in athletic training. Qualitative data sources included open response questions on the anonymous survey (pre- and post-coursework), focus group transcripts, and student artifacts (content-specific reflections). Institutional Review Board Approval was acquired. We recruited students in two CAATE-Accredited professional-level masters of athletic training programs to participate in the study via email and in-person. We provided all participants with a written informed consent statement that covered the study in its entirety, as well as separate informed consent statements for each individual component: the surveys, focus group interviews, and course artifacts, per the recommendation of the sponsoring institution IRB. 


\section{Participants}

We recruited a convenience sample of 14 students enrolled in a masters level professional athletic training program. The study took place in the students' first term in their academic program. All 14 students voluntarily agreed to participate in the study. Of the 14 participants, the age range was 21-29 years; 6 were female, 8 were male; the ethnic group distribution was $57 \%$ Caucasian, $29 \%$ Asian, $7 \%$ Hispanic and $7 \%$ Other (Table 1).

Table 1. Participant Demographics

\begin{tabular}{ccc}
\hline & Notal \\
\hline & N & $\%$ \\
\hline Age & 10 & $71 \%$ \\
$21-24$ & 4 & $29 \%$ \\
\hline Gender & & \\
Male & 8 & $57 \%$ \\
Female & 6 & $43 \%$ \\
\hline Race & & \\
Asian/Pacific Islander & 4 & $29 \%$ \\
Hispanic & 1 & $7 \%$ \\
White & 8 & $57 \%$ \\
Other & 1 & $7 \%$ \\
\hline International Student & & \\
Yes & 3 & $21 \%$ \\
No & 11 & $79 \%$ \\
\hline
\end{tabular}

\section{Data Collection \& Analysis}

We asked participants to complete one survey before and one survey after finishing all online learning modules. All participants completed the first survey and 9 participants completed the second survey. We invited potential participants via email to complete the online survey, which was distributed via Qualtrics. The email included assurance that participation in the study was voluntary and responses would be anonymous and private. The survey contained the complete informed consent statement showing approval from the sponsoring universities' institutional review boards. After reading the institutional review boards' approved statement about the study, participants were allowed to opt in or out of participation. Survey results were stored on the investigators' password-protected, university-owned computers. This procedure was repeated for the survey that was distributed after students completed the final module. The surveys were identical and included two demographic questions and four open-ended questions about their knowledge of soft skills and their experience with formal soft skills education (Table 2). Descriptive statistics were used to identify central tendency characteristics of the demographic items on the 2 surveys. For the data obtained from the 4 openended questions, we used a general inductive approach and an open-coding process. Each author completed the coding independently. We discussed our initial findings and agreed on the final codes for each question.

Table 2. Open-Ended Survey Questions

1. How would you best describe the concept of soft skills as they pertain to athletic training?

2. Describe the importance of soft skills to athletic training.

3a. Have you received any formal education regarding soft skills?

$3 b$. If yes, please describe: (please leave blank if you indicated soft skills in the previous question)

The soft skills curriculum included 11 separate online modules, each with a clearly defined theme (Table 3 ). We chose themes from previously published research. ${ }^{26}$ The principal investigators designed the online modules. Both investigators have curricular and instructional design training and experience with online education. They also have experience with instruction of soft skills. Each module included an explanation of the theme and its relevance to athletic training. Examples of online module format include the viewing of video-taped interviews with professionals in the field, completion of personality assessments, readings, and activities. We used student centered-active learning techniques to help students engage in the material and their own learning process. ${ }^{27}$ We designed activities to help students create personal connections to the materials and see the relevance of the themes. Each module also included a guided reflective writing assignment. Due to the individualized nature of the content, we selected reflective writing to promote application of concepts. All student reflections included in the study were de-identified prior to data storage and analysis. 
Table 3. Module Themesa

\begin{tabular}{|c|c|c|}
\hline Module Theme & Description & Content \\
\hline $\begin{array}{l}\text { Masters of Time \& Energy } \\
\text { Conscious }\end{array}$ & $\begin{array}{l}\text { Effective time and energy management skills, } \\
\text { organization strategies, tactics to combat } \\
\text { procrastination, and good personal care } \\
\text { strategies are covered. }\end{array}$ & $\begin{array}{l}\text { - Infographic and quiz on time management. } \\
\text { - Infographic, activity and a guided reflection } \\
\text { paper on sleep hygiene. } \\
\text { - Reading, activity and a guided reflection } \\
\text { paper on nutrition. } \\
\text { - StrengthFinder quiz, activity, and a guided } \\
\text { reflection paper. }\end{array}$ \\
\hline Listen \& Lead & $\begin{array}{l}\text { Verbal and non-verbal communication skills and } \\
\text { the value of recognizing and understanding } \\
\text { individual differences in order to adapt } \\
\text { communication style. }\end{array}$ & $\begin{array}{l}\text { - Reading and discussion on strength themes } \\
\text { and communication. } \\
\text { - Reflection paper on strengths, } \\
\text { communication, and relationships. }\end{array}$ \\
\hline Knowledgeable \& Curious & $\begin{array}{l}\text { Life-long learning, and the importance of seeking } \\
\text { new knowledge to help patients and to grow as a } \\
\text { health care provider and person. }\end{array}$ & $\begin{array}{l}\text { - Video interview with an athletic trainer and a } \\
\text { guided reflection paper. }\end{array}$ \\
\hline Decisive \& Confident & $\begin{array}{l}\text { Staying calm in times of crisis. Quick and } \\
\text { confident decision-making. Strategies to improve } \\
\text { confidence. }\end{array}$ & $\begin{array}{l}\text { - Reading, activity and a guided reflection } \\
\text { paper. }\end{array}$ \\
\hline $\begin{array}{l}\text { Dependability \& } \\
\text { Responsibility }\end{array}$ & $\begin{array}{l}\text { The importance of being honest, diligent, reliable, } \\
\text { and accountable. }\end{array}$ & $\begin{array}{l}\text { - Video interview with an athletic trainer and a } \\
\text { guided reflection paper. }\end{array}$ \\
\hline $\begin{array}{l}\text { Positive Attitude \& } \\
\text { Perseverance }\end{array}$ & $\begin{array}{l}\text { The benefits of an attitude of realistic optimism - } \\
\text { believing that success is possible with focus and } \\
\text { hard work. }\end{array}$ & $\begin{array}{l}\text { - Youtube video (happiness advantage), } \\
\text { reading, activity, and a guided reflection paper }\end{array}$ \\
\hline Prepared \& Adaptable & $\begin{array}{l}\text { The importance of being organized and ready, as } \\
\text { well as being flexible. The importance of being } \\
\text { able to make a plan and modify it as needed. }\end{array}$ & $\begin{array}{l}\text { - Video interview with an athletic trainer and a } \\
\text { guided reflection paper. }\end{array}$ \\
\hline $\begin{array}{l}\text { Growth Mindset \& Action } \\
\text { Oriented }\end{array}$ & $\begin{array}{l}\text { Belief that knowledge and abilities can be } \\
\text { developed through hard work and dedicated } \\
\text { effort toward a goal. }\end{array}$ & $\begin{array}{l}\text { - Youtube video (happiness advantage), } \\
\text { reading, activity, and guided reflection paper. }\end{array}$ \\
\hline Observant \& Exact & $\begin{array}{l}\text { The value of paying attention to details, and } \\
\text { being conscientious about following directions. }\end{array}$ & $\begin{array}{l}\text { - Video interview with an athletic trainer and a } \\
\text { guided reflection paper. }\end{array}$ \\
\hline $\begin{array}{l}\text { Good Character \& } \\
\text { Trustworthy }\end{array}$ & $\begin{array}{l}\text { Honesty, credibility, and having high ethical } \\
\text { standards. }\end{array}$ & $\begin{array}{l}\text { - Video interview with an athletic trainer and a } \\
\text { guided reflection paper. }\end{array}$ \\
\hline Givers \& Takers & $\begin{array}{l}\text { The importance of being generous as well as } \\
\text { accepting help when needed. }\end{array}$ & $\begin{array}{l}\text { - Video interview with an athletic trainer and a } \\
\text { guided reflection paper. }\end{array}$ \\
\hline
\end{tabular}

a Module themes and description from Davlin-Pater \& Rosencrum (2019)

After students had completed all modules, we invited them to participate in a semi-structured focus group interview lead by one of the principal investigators. Thirteen of the fourteen participants completed the focus group interview. The interviews were audiorecorded, transcribed verbatim by the principal investigators, checked for accuracy by each principal investigator, and then member checked for accuracy of meaning. Transcripts were stored in a word (version 97-2004; Microsoft Inc., Redmond, WA) document on a password-protected, university-owned computer. Focus group participants completed an additional informed consent form prior to participating. We gave all participants pseudonyms in the transcripts to protect participant anonymity. We asked focus groups 2 questions about knowledge of soft skills, the meaning of soft skills in the practice of athletic training, and 3 questions about the modules they completed, as well as probing questions to clarify meaning, as needed (Table 4).

Table 4. Focus Group Questions

1. How would you describe soft skills?

2. What do soft skills mean for your clinical practice as an athletic training student?

3. How did you feel about the online modules regarding soft skills?

4. During what soft skill module(s) did you learn most?

5. During what soft skill module(s) did you learn least? 
In an effort to minimize the unlikely psychological risk to participants in this project, data analysis began after the courses were completed and student final grades were submitted. We analyzed the data using constant comparative method and inductive approach to explore trends and themes in the data. After initial determination of the themes, the second researcher conducted content analysis to confirm the initial researchers findings. Any discrepancies between researchers were discussed and resolved. Data triangulation was accomplished via the survey, focus group transcript, and reflection data. Data trustworthiness was supported by the use of member checking for focus group transcript accuracy, and peer debriefing between the principal investigators. ${ }^{28}$

\section{RESULTS}

Only one of the participants indicated that they had taken part in any type of formal soft skills training prior to participation in this study. In the pre-course work survey, results revealed that most of participants had an inaccurate or incomplete understanding of what soft skills were and why soft skills are important in the profession of athletic training. Following completion of the modules, all participants were able to adequately describe the concept of soft skills as they pertain to athletic training and articulate the importance of soft skills to athletic training.

Three main themes emerged from the data regarding graduate student perception of learning soft skills in an online format. Participants in the study spoke consistently to the following areas: 1) value of soft skills, 2) interpersonal communication and collaboration, and 3) personal growth. Several supporting themes bolstered each of these areas, and linked the main themes to a general appreciation for the soft skills online modules.

\section{Value of Soft Skills}

Participants universally saw the value in developing soft skills and adopting the professional behaviors that were included in the curriculum. Participants spoke to the importance of soft skills at many points throughout the study. For example one participant said: ".. what we are learning now, we will be using later. It's not just a throw away thing. It is stuff we can use in our profession and outside our profession for the rest of our lives." Additionally, in the module focusing on the value of being knowledgeable and curious, one participant wrote:

To be a life-long learner means that you are constantly adapting to new information and never stop learning about new techniques and new methods. This is something that really appeals to me in the field of Athletic Training because I love to learn about new things and how something can be helpful or if there are new things that work better than old techniques.

In several of the modules, students had the opportunity to view videos of athletic trainers speaking about various soft skill themes. Students wrote guided reflections on the videos, which were designed to make them think about what the soft skills meant to them personally, and what it meant in the context of athletic training practice. The following are examples of reflection writings from the good character \& trustworthy module. One participant wrote about what it meant to him: "Having good character and being trustworthy is about being a reliable person that truly cares about those around them." Students recognized through the good character and trustworthy module video that patient care is the top priority, but that there can be outside pressures that could make this difficult. One participant wrote: "The thing that (the AT in the video) said that was most interesting was at the very end, where he talks about the priority being on the health and well-being of the athlete, and not winning. That is a big problem that I am a bit nervous about." Another participant wrote: "... it is vital to care for the athlete regardless of the repercussions. I know that this is crucial within the profession." Participants also recognized the benefits of behaving with good character and being trustworthy to aid in the relationship the athletic trainer has with patients; as one participant wrote:

What stood out to me is the fact that (the AT's) athletes trust him with (the AT's) athletic training skills that they reach out to (the AT) for other things such as mental health, personal life, or even struggles with teammates ... I want to be able to have that trust and relationship with athletes to where they can rely on me and come to me with any problem they may have.

Participants acknowledged the value of the soft skills in the modules and saw the benefits in adopting the behaviors outlined in the curriculum.

\section{Interpersonal Communication and Collaboration}

Participants appreciated being able to learn more about themselves and others in the context of athletic training practice throughout the curriculum. Participants also valued learning more about their own communication style for the purpose of understanding their interactions with others. The use of StrengthsQuest $\mathbb{Q} /$ StrengthsFinder $^{\circledR}$ at the beginning of the soft skills curriculum set the tone for introspection for participants in the study. The Clifton StrengthsFinder online assessment is a tool designed to identify the top 5 talents specific to each person. The Clifton StrengthsQuest program helps students integrate the identified talents into their self- 
view while providing an effective framework for discussing individual differences, empathy, and communication.

Using the StrengthQuest results, students were asked to imagine working with a peer, who had different strengths, to provide medical coverage for a big event. One participant noted that she would want to just jump into things, but would need to adapt by "listening to the whole plan before acting", because that is what her partner would need to be effective. Another participant spoke to the benefit of dovetailing strengths, including using the strengths of each other to accomplish tasks, and trusting their colleague to support their weaknesses:

... I believe we would be an effective team because my theme would be Discipline and (other student's) is Activator. Working with (student) would be good because he would get us ready mentally and physically to start preparing for the event. I feel since I am good with routines and setting things up, we would be ready with the stuff we needed to bring out quickly.

Participants commonly identified soft skills as vital to effectively working with colleagues, patients, and other stakeholders. One participant described soft skills as "social skills but in a professional manner." While others linked the necessity of interpersonal skills in athletic training to the dependence on social interaction in practice; one participant calling athletic training fundamentally a "social occupation."

\section{Personal Growth}

Participants identified components of both the content of the online soft skills modules and the reflective process as being impactful for them. The reflection activities also allowed the instructors to note how students were growing and evolving through the soft skills curriculum. Participants noted that they felt they grew in their self-awareness, for example:

I think the one (module) that stuck out to me was the Givers and Takers, because I had a really easy time coming up with the takers portion, but I couldn't really think of a lot of the givers ones ... The taking - oh yea, that one person helped me that one time and it was really impactful. But, I don't remember if I have ever been that impactful for someone else - and I probably have, I just don't think about it.

That comment went on to highlight a similar appreciation for one of their blind spots in regard to their behaviors with others. Another participant added: "... (Givers \& Takers) also stood out to me. But it was also the flip of that. I felt I had a tough time remembering when I went out and asked for help... I want to figure it out myself, but I know that I should ... it would have been a lot easier if I had asked for help."

In many of the modules, we asked students to try a new strategy for a 4-5 days and then reflect on how it worked (or did not work). Through this process they learned more about themselves, and adopted new behaviors. For example, one participant wrote about adopting a strategy to improve confidence,

I think that the strategy I adopted is going pretty well. I chose to try not to second guess myself or dwell on decisions too long. I still need to work on my confidence with this one, because I believe that I know the material pretty well, I just need to not second guess myself when it comes to performing, either in a test or a practical application.

Many participants noted that the process of learning about soft skills resulted in personal growth. For example, one student noted that the module on confidence had a significant impact on them. He mentioned how the concepts could be applied to his life. When participants were asked about which modules they thought they learned the most, there were a variety of answers, with a common theme of awareness and personal growth. For example: "I think the Decisive and Confident one was the most important to me because ... sometimes I am not the most confident, but, by practicing my skills over and over again, it helps me stay calm and just trust myself." Another student said: "I think the Good Character and Trustworthy (module) was kind of helpful for me because it showed that in the athletic training facility - if you don't act a certain way, then the athletes aren't going to respect you and that's going to affect your credibility and how you interact with them on a daily basis."

A few participants mentioned that even the modules that were less impactful for them, were still constructive. For example one participant said: "I would say each module had something you can take away from it... It gave you something to ponder whether you used it or not, something to just give you more of a self-awareness, something to think about when you handle situations." A few other participants noted that although they were more self-aware, they chose not to change. For example, one participant said: "... I don't want to say I am set in my ways, but I am a chronic procrastinator ... I have told myself that I do my best work when I am under pressure. So I think that is the (module titled "Masters of Time \& Energy Conscious") I learned the least - I learned a lot, but 
I didn't put it into practice." While not all concepts may have resulted in behvioral changes, overall the participants saw value in learning about the various soft skills and reflecting on their thoughts and choices.

\section{DISCUSSION}

We aimed to examine student perceptions of online learning modules designed to promote professional socialization and soft skill development in professional level athletic training students during their first term in their education program. Previously, DavlinPater \& Rosencrum described a method of explicitly teaching 11 categories of soft skills to preprofessional athletic training students in an undergraduate setting using an in-person format. ${ }^{26}$ This formed the foundation of the new online curriculum which was then updated and redesigned for graduate students. The curriculum was effective in helping students understand and appreciate the value of soft skills and the importance of effective interpersonal communication and collaboration. It further allowed students to explore positive habits and examine the thoughts and behaviors that lead to feelings of personal growth. These findings reinforce the value of using an overt curriculum with opportunities for self-reflection in the development of professional behaviors. ${ }^{29}$ While there may be some perceived incongruency in teaching a primarily in-person skill in an online format, we did see evidence in student reflections and interviews that participants were able to practice and apply these skills in their daily life and clinical experiences.

Following completion of the modules, participants were able to accurately articulate the concept and importance of soft skills as they pertain to athletic training. Throughout the online curriculum, participants appreciated soft skills and their significance to high quality clinical practice. They identified the connection between practicing soft skills and other fundamental skills involved in the profession of athletic training. Participants associated working on areas such as mental skills, mindset, punctuality, observation skills and more, with the quality of care they wish to provide for their patients. Participants found significant value in the use of reallife examples and learning from clinicians outside of their faculty. They also felt that the opportunities to apply the soft skills content was truly vital and perceived less value in the content they deemed more difficult to practice. Thus, a possible benefit of the soft skills curriculum was that students engaged in the theoretical and then were able to quickly practice it in their day-to-day life.

Athletic trainers rely on soft skills to work effectively as health care team members and provide care for their patients. ${ }^{18}$ Soft skill aquisition in athletic training have previously been explored through role modeling and as part of the hidden curriculum. ${ }^{18,19} \mathrm{As}$ role modeling and hidden curriculum are not overt pedagogies, they may result in inconsistent student experiences. ${ }^{30} \mathrm{It}$ may also result in false assumptions and misunderstandings between students and preceptors or instructors. ${ }^{29}$ Sullivan \& Thiessan warn that students may be "labeled as unprofessional when the actual issue may be lack of knowledge about the nuances of professionalism in different contexts." ${ }^{31(\mathrm{p} 3)}$ Thus, explicitly teaching students, from a practical perspective, how to approach their professionalism may assist in their professional integration and socialization. Additionally, an intentional focus on learning professional behaviors and promoting development soft skills early in an education program should afford students with more opportunities to consciously apply and practice these behaviors and skills in the clinical setting.

In the present study, the online method of course delivery was viewed positively by participants. The accessibility of the online activities and content added ease and convenience to an otherwise complex and rigorous program of study. Students who participated in these modules were in their first term of their respective graduate professional level athletic training programs, and truly appreciated how direct and concise the activities were. Many noted that while the soft skills assignments were "easy", they found them useful, and purposeful for continued engagement in and application of the content. Participants noted that their programs as a whole were stressful and rigorous, but finding some area of ease, while still making progress was comforting for them. Additionally, the ability to augment student development of these soft skills in a manner that was time efficient and primarily outside of in-person class meetings added value for the professors' management of academic learning time.

Due to the time constraints for delivery of content, educators may feel challenged to add more to their curriculum. Previous research has shown that online, self-paced modules can be an effective method for delivering content related to athletic training and patient care. ${ }^{32-36}$ Recently educators in occupational therapy, in an effort to advance emotional intelligence, used a series of online modules due to the low cost, flexibility, and convenience that this format allows. ${ }^{32}$ The authors of the current study also chose an online module format for similar reasons and found it to be effective and time-efficient way to integrate this type of content while still allowing class time to meet other accreditation standards. Creation of online modules can be time consuming. However, once constructed they can be used again without much additional effort. ${ }^{33}$ In the case of this study, the online format allowed for identical modules to be used by students attending two separate academic programs in different parts of the country.

(C) The Internet Journal of Allied Health Sciences and Practice, 2021 


\section{Limitations and Future Direction}

There were some limitations in the current study which warrant discussion. First, a response rate of only $57 \%$ was obtained for the second survey. In the future, participants should be more effectively recruited for completion of the post-curriculum survey for best pre-post comparison. Second, the sample consisted of a convience sample of students enrolled in two entry level graduate programs. This small sample size could affect the applicability of the results to a larger population. Future research in the area of professional behaviors and soft skills development in athletic training students should focus on student outcome assessment, and preceptor perception of the soft skills. Much like the scope of practice of athletic training, professional behaviors and soft skill expectations evolve over time, and as such, constant evaluation and adjustment of this content should also be addressed.

\section{CONCLUSION}

In athletic training, soft skills have been identified as valuable to educators, athletic trainers, and employers. $7,9,10-12,14,18$ Athletic trainers as a cornerstone to collaborative healthcare teams, rely on soft skills to provide excellent interprofessional care for their patients. ${ }^{15}$ Additionally, teaching soft skills in an academic program is thought to increase students' self-efficacy, self-esteem, confidence, and career success. ${ }^{37}$ The use of online learning methods may offer an opportunity for overt instruction in soft skills in athletic training curriculum.

\section{REFERENCES:}

1. Charkravarti S, Charkraborty S. The Teaching of Soft Communication Skills in Entrepreneurship Development Courses at the +2 Level in India. IUP Journal of Soft Skills. 2018;12(4):30-40.

2. Hepsiba S. Mastery of Soft Skills by J. K. Rowling's Harry Potter. Language in India. 2020;20(4):98-103.

3. Robles MM. Executive Perceptions of the Top 10 Soft Skills Needed in Today's Workplace. Business Communication Quarterly. 2012;75(4):453-465.

4. Commission on Accreditation of Athletic Training Education. 2020 standards for accreditation of professional athletic training programs. https://caate.net/wp-content/uploads/2018/09/2020- Standards-for-Professional-Programscopyedited-clean.pdf. Accessed January 30, 2019.

5. American Physical Therapy Association. Minimum required skills of physical therapist graduates at entry level. https://www. apta.org/uploadedFiles/APTAorg/About_Us/Policies/BOD/Education/MinReqSkillsPTGrad.pdf. Accessed January 25, 2019.

6. American Occupational Therapy Association. 2011 Accreditation Council for Occupational Therapy Education (ACOTE) standards. https://www.aota.org/ /media/Corporate/Files/ EducationCareers/Accredit/Standards/2011Standards-and- Interpretive-Guide.pdf. Accessed January 30, 2019.

7. Compton S, Simon JE, Harris LL. Supervisor perceptions of newly credentialed athletic trainers' transition to practice. Athl Train Educ J. 2020;15(3):201-211.

8. Carr WD, Volberding J. Employer and employee opinions of thematic deficiencies in new athletic training graduates. Athl Train Educ J. 2012;7(2):53-59.

9. Carr WD, Thomas S, Paulsen J, Chiu J. Characteristics of athletic training students that preceptors find desirable. Athl Train Educ J. 2016;11(1):27-31.

10. Handlos JL, Ludwig G. Leadership proficiency: perspectives of athletic trainers new to practice. Athl Train Educ J. 2019;14(3):191-197.

11. Kahanov L, Andrews L. A Survey of Athletic Training Employers' Hiring Criteria. J Athl Train. 2001;36(4):408-412.

12. Kutz MR. Importance of Leadership Competencies and Content for Athletic Training Education and Practice: A Delphi Technique and National Survey [dissertation]. Boca Raton, FL: College of Business and Management, Lynn University; 2006.

13. Kutz M. Leadership in athletic training: implications for practice and education in allied health care. $J$ Allied Health. 2010; 39(4):265-279.

14. Massie BJ, Strang AJ, Ward RM. Employer perceptions of the academic preparation of entry-level certified athletic trainers. Athl Train Educ J. 2009;4(2):70-74.

15. Henderson J. The 2015 Athletic Trainer Practice Analysis Study. Omaha, NE: Board of Certification; 2015.

16. Tsang A. The Evolving Professional (EP) Concept as a Framework for the Scholarship of Teaching and Learning. International Journal for the Scholarship of Teaching and Learning. 2010;4(1):1-10.

17. Tsang A. Students as Evolving Professionals - Student Perceptions of the Evolving Professional (EP) Concept as a Professional Socialization Approach. Australian Association for Research in Education: Inspiring Innovative Research in Education. 2009;pg1-13.

18. Peer KS, Schlabach GA. The professional values of program directors and head athletic trainers: the impact of the hidden curriculum. Athl Train Educ J. 2011;6(4):194-201. 
19. Johnson C, Hammond L. Learning professionalism on the touch-line: pedagogical challenges and recommendations. Athl Train Educ J. 2018;13(3):290-298.

20. Page G. Professional socialisation of valuers: what the literature and professional bodies offer. International Education Journal. 2005;5(5),105-116.

21. Bowman TG, Dodge TM. Factors of persistence among graduates of athletic training education programs. J Athl Train. 2011;46(6):665-671.

22. Mazerolle SM, Bowman TG, Dodge TM. Athletic training student socialization part l: socializing students in undergraduate athletic training programs. Athl Train Educ J. 2014;9(2):72-79.

23. Mazerolle SM, Bowman TG, Dodge TM. Athletic training student socialization part II: socializing the professional master's athletic training student. Athl Train Educ J. 2014;9(2):80-86.

24. Starks H, Trinidad SB. Choose your method: a comparison of phenomenology, discourse analysis, and grounded theory. Qualitative Health Research. 2007;17(10):1372-1380.

25. Qualitative inquiry and research design; choosing among five approaches, $3 \mathrm{~d}$ ed. Reference \& Research Book News. 2012;27(3).

26. Davlin-Pater C, Rosencrum E. Promoting Soft-skill Development in Preprofessional Athletic Training Students. Athl. Train Educ J. 2019;14(1):73-79.

27. Weimer M. Learner-Centered Teaching : Five Key Changes to Practice. Second edition. Jossey-Bass; 2013.

28. Thomas DR. A general inductive approach for analyzing qualitative evaluation data. Am J Eval. 2006;27(2):237-246.

29. Reiter K, Helgeson L, Lee SC. Enhancing Professionalism Among OT Students: The Culture of Professionalism. Journal of Occupational Therapy Education. 2018;2(3).

30. Dutton L, Selheim D. The Informal and Hidden Curriculum in Physical Therapist Education. J Phys Ther Educ. 2014;28(3),50-63.

31. Sullivan TM, Thiessen AK. Occupational Therapy Students' Perspectives of Professionalism: An Exploratory Study. Open J Occup Ther. 2015;3(4).

32. Calabrese J, Lape JE, Delbert T. Use of Online Educational Modules to Improve Occupational Therapy Students' Knowledge and Perceptions of Their Emotional Intelligence Skills: An Evidence-Based Pilot Study. Journal of Occupational Therapy Education. 2019,3(3):12-20.

33. Huxel Bliven KC, Anderson BE, Makin IRS. Commentary: integrating diagnostic ultrasound into athletic training education programs. Athl Train Educ J. 2018;13(4):367-371.

34. Lam KC, Hoch MC, Anderson BE, Bay RC, Welch CE. The effectiveness of online video modules in improving knowledge and hands-on clinical skills: a pilot study. Athl Train Educ J. 2015;10(suppl):S14-S15.

35. Manspeaker SA, Feld SD, Hankemeier DA, Kirby JL. Integration of interprofessional education within the didactic aspect of athletic training programs. Athl Train Educ J. 2020;15(3):168-176.

36. Winkelmann Z, Eberman LE. The confidence and abilities to assess a simulated patient using telemedicine. Athl Train Educ J. 2020;15(2):132-147.

37. Brown LS. Soft Skill Development in the Higher Education Curriculum: A Case Study. IUP Journal of Soft Skills. 2018;12(4):7-29. 